\title{
Pressurized pulse irrigation with saline reduces surgical-site infections following major hepatobiliary and pancreatic surgery - Randomized Controlled Trial.
}

\author{
Mehrdad Nikfarjam ${ }^{1}$, Laurence Weinberg ${ }^{2}$, Michael A Fink ${ }^{1}$, Vijayaragavan \\ Muralidharan $^{1}$, Graham Starkey ${ }^{1}$, Robert Jones ${ }^{1}$, Kevin Staveley-O'Carroll ${ }^{3}$, \\ Christopher Christophi ${ }^{1}$
}

University of Melbourne Department of Surgery ${ }^{1}$ and Anaesthesia ${ }^{2}$, Austin Health, Heidelberg, Victoria, Australia. Medical University of South Carolina, Department of Surgical Oncology, Charleston, South Carolina, USA

\section{Short Title:}

Pulse irrigation reduces surgical site infections

Key Words: Surgical wound infection; Treatment Outcome; Humans; Clinical trial; Antibiotic Prophylaxis

\author{
Corresponding Author \\ Mehrdad Nikfarjam MD, PhD, FRACS \\ University Department of Surgery \\ Austin Health, LTB 8, \\ Studley Rd, Heidelberg \\ Melbourne, Victoria, 3084 \\ Australia \\ Tel: +61394965466 \\ Fax: +6139458 1650 \\ Email: mehrdad.nikfarjam@gmail.com
}




\section{ABSTRACT}

BACKGROUND: Surgical site infections (SSI) are a significant cause of postoperative morbidity. Pressurized pulse irrigation of subcutaneous tissues may lower infection rates by aid in the debridement of necrotic tissue and reducing bacterial counts compared to simply pouring saline into the wound.

METHODS: One hundred and twenty-eight patients undergoing laparotomy extending beyond 2 hours were randomized to treatment of wounds by pressurized pulse lavage irrigation ( $<15 \mathrm{psi}$ ) using 2 liters normal saline (pulse irrigation group), or to standard irrigation with 2 liters normal saline poured into the wound, immediately prior to skin closure (standard group). Only elective cases were included. All cases were performed within a specialized hepatobiliary and pancreatic surgery unit.

RESULTS: There were 62 patients managed by standard irrigation and 68 by pulse irrigation. The groups were comparable in most aspects. Overall there were $16(13 \%)$ surgical site infections. Significantly fewer SSI occurred in the pulse irrigation group (4 (6\%) versus $12(19 \%) ; \mathrm{p}=0.032)$. On multivariate analysis, the use of pulse irrigation was the only factor associated with a reduction in SSI with and odds ratio of 0.3 (95\% Confidence Interval 0.1-0.8; $\mathrm{p}=0.031$ ). In contrast, hospital length of stay of greater than 14 days was associated with increased infections with an odds ratio of 7.6 (95\% Confidence Interval 2.4-24.9; $\mathrm{p}=0.001$ ).

CONCLUSIONS: Pulse irrigation of laparotomy wounds in operations exceeding 2 hours duration reduced SSI after major hepatobiliary pancreatic surgery. (Australian New Zealand Clinical Trials Registry, ACTRN12612000170820). 


\section{INTRODUCTION}

Surgical site infections (SSI) are a major cause of post-operative morbidity and increased hospital costs. ${ }^{1,2}$ The true incidence of SSI varies according to the definition utilized and the surgical procedure performed. Infection risks are lowest with clean operations and highest in emergency cases involving a contaminated field. ${ }^{3}$ Patient factors, glycemic control, operative extent, compliance with basic principles such as appropriate skin preparation and antibiotic prophylaxis, along with surgical technique, are all important factors affecting the risk of surgical site infections. ${ }^{3,4}$

In abdominal surgery, SSI rates are likely to be higher than reported. ${ }^{5}$ Whilst most SSI are minor, many require active and often prolonged treatment, which may increase pharmaco-economic expenditure and place additional burden on utilization of healthcare resources. Randomized trials have examined various techniques to reduce infection rates. Choice of antiseptic use and the administration of pre-operative antibiotics are the foci of several large studies. ${ }^{6-9}$ Wound protection barriers in colorectal surgery appear to have some potential benefit, especially if spillage of bowel content directly into the subcutaneous tissue is a possibility. ${ }^{10-12}$ Irrigation of wounds to reduce SSI after major abdominal surgery has not been studied in a randomized manner, with most of the data on this topic limited to the orthopedic literature, utilizing pressurized pulse irrigation devices to irrigate subcutaneous and

deep tissues ${ }^{13-16}$ Pressurized $(<15$ psi) pulseirrigation of subcutaneous tissue after 
prolonged operations may reduce bacterial counts and aid the removal of desiccated tissue that can act as a nidus for infection. ${ }^{15,17}$

In a previous study examining the rate of laparotomy wound infections relating to major hepatobiliary and upper gastrointestinal surgery, the use of pressurized pulse irrigation to wash out laparotomy wounds with saline prior to skin closure appeared to reduce SSI. ${ }^{18}$ However, this was not a randomized study and was limited to operative cases of 4 hours or greater in duration. A randomized trial was devised to examine the effect of pressurized pulse irrigation of laparotomy wounds for elective operations exceeding 2 hours within a hepatobiliary pancreatic unit.. 


\section{PATIENTS AND METHODS}

\section{Patient population}

Consecutive patients undergoing major elective abdominal operative procedures at a tertiary hepatobiliary and pancreatic surgery unit between 2010 and 2012 were enrolled. Institutional review board (IRB) approval was obtained to conduct the trial at Austin Health, Heidelberg, Melbourne, Australia and Warringal Private Hospital, Heidelberg, Melbourne, Australia. The study was registered with the Australian New Zealand Clinical Trials Registry (ACTRN:12612000170820). All patients undergoing elective operative procedures within the unit requiring a laparotomy were identified. Operations were performed by one of six specialist hepatobiliary pancreatic surgeons.

Inclusion criteria included adult patients undergoing an elective open abdominal operation that was anticipated to extend beyond 2 hours. Laparoscopic procedures were excluded.

\section{Randomisation}

Randomisation was performed following abdominal fascial closure, immediately prior skin closure. Grouping allocation was determined by sealed envelope selection. 
Blocks of 20 patients were randomized at one time. Diabetic patients were randomized separately to achieve close to even distribution in each group .(Figure 1).

\section{Preoperative assessment}

Demographic data including, age, sex, American Society of Anesthesiologist (ASA) classification, body mass index (BMI), associated medical conditions, base-line blood tests performed in pre-operative testing clinic, and indications for surgery, were recorded.

\section{Operative procedures}

Operative details were documented. This included the indications for surgery, the organs resected, the surgical time and the need for intra-operative blood transfusions. The type of laparotomy varied according to surgeon preferences. All cases were elective operations and none was performed for treatment of an established intraabdominal infection.

\section{Anesthesia management}

Anesthesia was managed by a group of specialist anesthesiologists using a protocol designed to standardize patient care. Induction of anaesthesia was achieved with balanced technique combining intravenous midazolam 0.02-0.03mg/kg IV (Sandoz Pty Ltd, Pyrmont, NSW, Australia), fentanyl 1-2 ug/kg IV (AstraZeneca Australia), propofol 1-3 mg/kg IV (Fresenius Kabi Australia Pty Ltd, Pymbie, NSW, Australia). Following induction of anesthesia all patients received dexamethasone phosphate $8 \mathrm{mg}$ IV (Aspen Pharmacare Australia Pty Ltd, St Leonards, NSW, Australia) as part of 
routine antiemetic prophylaxis. Anesthesia was maintained with sevoflurane or desflurane at inspired concentrations of 0.5-0.1 MAC, with a fractional inspired oxygen-air concentration of 0.5 , and an infusion of remifentanil $0.1-0.3 u \mathrm{~g} / \mathrm{kg} / \mathrm{min}$ IV (Ultiva®, GlaxoSmothKline Australia Pty Ltd. Mechanical ventilation maintained end tidal $\mathrm{pCO}_{2}$ between 35-40 mmHg. Routine monitoring included continuous electrocardiography, pulse oximetry, capnography, invasive arterial blood pressure, central venous pressure, urine output and core body temperature. Intra-operative normothermia was maintained with warm fluids (Medi-Temp II, Gaymar Industries, NY, USA) and a forced-air warming device (WarmAir, Convective Air Therapy, Cincinnati Sub-zero, Connecticut, USA). Urine output was maintained at greater than $0.5 \mathrm{ml} / \mathrm{kg} / \mathrm{h}$, and systolic blood pressure was maintained within $20 \%$ of the preoperative value.

In keeping with our institutions antibiotic prophylaxis protocol, at induction of anesthesia all patients received Ampicillin 1g IV (Aspen Pharmacare Australia Pty Ltd, St Leonards, NSW, Australia), Gentamicin IV (2 mg/kg) (Hospira Pty Ltd, Melbourne, VIC, Australia) and Metronidazole 500mg IV (Hospira Pty Ltd, Melbourne, VIC, Australia). Antibiotics were continued for 24 hours post operatively. In cases of penicillin allergy, Vancomycin 1g IV (Hospira Pty Ltd, Melbourne, VIC, Australia) or Cephazolin 1g IV (Alphapharm Pty Ltd, Millers Point, NSW, Australia) was administered according to the particular sensitivity reaction.

Where appropriate, hair removal from the abdominal wall was performed immediately before the abdomen was prepped using clippers. The abdomen was prepped with alcohol based iodine unless there was a contraindication. An Ioban ${ }^{\mathrm{TM}}$ 
$\left(3 \mathrm{M}^{\mathrm{TM}}\right.$ North Ryde, NSW, AUSTRALIA) steri-drape was applied prior to initial skin incision with a scalpel. The Thomson surgical retractor (Traverse City, MI, USA) is the preferred wound retracting system, with moist saline soaked packs applied to the wound edges that are intermittently moistened during the course of the case. Operative procedures were performed according to the given indication.

In all cases, prior to abdominal closure, the peritoneal cavity was irrigated with least 3 liters of warm saline without any added antibiotics. The abdominal wall was reapproximated by mass closure using looped size 1 Polydioxane (PDS) sutures (Johnson and Johnson Co. Melbourne, Australia) with interrupted 1 Nylon sutures (Johnson and Johnson Co. Melbourne, Australia) in some cases. If the case exceeded two hours duration, patients were then randomized immediately prior to skin closure to irrigation of subcutaneous tissue by standard method (Standard group), or to a pulsatile lavage irrigation device (Pulse irrigation group).

\section{Wound Irrigation Technique}

Following closure of the fascia in the standard group, 2 litres of normal saline at room temperature was poured into the subcutaneous tissue without any agitation. In the pulsatile lavage group (Pulse irrigation group), the Surgilav® Irrigation device (Stryker® Instruments, USA) was used after fascia closure to irrigate the surgical wound with 2 litres of normal saline at room temperature. This device delivers saline at a pressure of close to 15 pounds per square inch (psi), but not exceeding it, though a cone shaped applicator. 
Excess fluid was removed from the subcutaneous tissue with application of a dry pack. Subcutaneous drainage or closure was not undertaken. The skin was reapproximated with continuous subcuticular 3/0 Monocryl sutures (Johnson and Johnson Co. Melbourne, Australia). Skin staples were not used in any cases. A Duoderm dressing (Convatec, Clayton, VIC, Australia) was applied to the wound.

\section{Post-operative outcome}

Postoperatively, all patients were nursed in a high dependency or intensive care unit for at least 24 hours and then transferred to the surgical ward for ongoing care. Patients were managed in a standard manner according to the operative procedure. Glycemic control (glucose $<8 \mathrm{mmol} / \mathrm{l}$ ) was maintained post-surgery using an insulin sliding scale. Nasogastric tube and abdominal drain usage were recorded.

Complications, length of stay and readmissions were noted. In cases of re-laparotomy, wound management was kept the same as initial randomization. Antibiotics were administered for only 24 hours post-operatively as a routine. If antibiotics were given at any time after 24 hours, this was recorded. Abdominal dressings were removed for initial wound assessment at one week following surgery, unless there were concerns of possible infection prior to this time. Wounds were assessed again 2 weeks following surgery and thereafter as indicated. Minimum follow-up after surgery was 1 month.

Wound infection determination

Wounds were determined as infected based on strictly defined criteria which included : 1. Purulent drainage, with or without laboratory confirmation, from the superficial 
incision. 2. Organisms isolated from an aseptically obtained culture of fluid or tissue from the superficial incision. 3. At least one of the following signs or symptoms of infection: pain or tenderness, localized swelling, redness, or heat and superficial incision is deliberately opened by surgeon, unless incision is culture-negative. 4 . Diagnosis of superficial incisional SSI by the surgeon or attending physician. ${ }^{5}$ Nonwound related complications were defined as any adverse event not considered a normal part of post-operative recovery. Patients were monitored by a dedicated acute pain service and reviewed daily for any complications arising from their analgesic regime.

\section{Statistical Analysis}

Sample size calculations were based on our previous study demonstrating SSI rates of approximately $30 \%$ after prolonged intra-abdominal surgical procedures. ${ }^{18}$ Assuming that the rate of SSI could be reduced from $30 \%$ to $15 \%$ by pulse irrigation of wounds, then 128 patients (64 per group) provided an $80 \%$ power for detecting this difference, at a significance level of 0.05. (http://stat.ubc.ca/ rollin/stats/ssize/index.html). Results are expressed as median (range) unless otherwise stated. Comparisons between categorical variables were made by Chi Square or Fisher's exact test, where appropriate. Non-categorical variables were assessed by the Mann-Whitney U test. A statistical software package (SPSS Version 19.0; USA IBM Co, Armonk, NY, USA) was used for analysis. Multivariate analysis was undertaken using a backward stepwise logistic regression model to identify factors independently associated with SSI, including all factors where the $\mathrm{P}$ value was less than 0.1 on univariate analysis. Odds ratios $(\mathrm{OR})$ and $95 \%$ confidence intervals $(\mathrm{CI})$ were noted. 


\section{RESULTS}

\section{Patient Characteristics}

A total of 137 patients were enrolled with 8 cases not reaching the 2 hours duration required for randomization. The grouping of patients is shown in Figure 1. There were no significant differences between the groups in terms of baseline characteristics (Table 1).

\section{Surgical details}

The indications for surgery and operative details are noted in Table 2. The major indication for surgery was malignancy. Pancreatic operations included pancreaticoduodenectomy and distal pancreatectomy. Liver operations included minor and major hepatectomies. Biliary operations included bile duct resections and isolated biliary bypass procedures. There were no differences in operation types between the two groups. However, an abdominal drain was more commonly utilized in the standard group (66\% versus $48 \%$; $\mathrm{p}=0.045$ ). In the standard group, there was a significantly greater use of a reverse $\mathrm{L}$ incision $(37 \%$ versus $17 \% ; \mathrm{p}=0.033)$. In this series, $47 \%$ of cases were performed by one surgeon. Six specialists surgeons in total participated in this study with some differences noted in the random assignment of patients to either standard or pulse irrigation groups $(\mathrm{p}-=0.023)$. There were no other statistically significant differences between the two groups. 


\section{Post-operative outcomes and complications}

The rate of overall complications and non-wound related complications were similar between the groups (Table 3). However, there were significantly fewer wound infections in the pulse irrigation group (4 (6\%) versus $12(19 \%) ; \mathrm{p}=0.032)$. All 4 wound infections in the pulse irrigation group were of a superficial nature requiring simple drainage and a course of antibiotics. Two of 12 wound infections in the standard treatment group required major debridement, with prolonged course of dressings. One of these patients had partial abdominal wall dehiscence. The remaining were managed by simple drainage and antibiotics. Of the 16 patients with wound infections, $14(88 \%)$ had antibiotics continued for longer than 24 hours postsurgery. One patient had wound cellulitis with no wound cultures performed. Of the remaining 15 patients that had cultures performed, the following were isolated; mixed skin flora (8), mixed enteric flora (3), Enterobacter cloacae (1), Staphylococcus aureus (1), Stenotrophomonas maltophilia (1), and in one case there was no growth despite multiple samples examined. Overall $56 \%(n=72)$ of patients had prophylactic antibiotics continued beyond 24 hours. This was based on physician request, often in response to early post-operative fever, in the absence of definite infective focus.

With regard to other post-operative outcomes, including transfusion rates, readmissions and length of stay, there were no significant differences between the groups (Table 3).

\section{Factors associated with wound infections}

Various factors possibly associated with SSI were examined by univariate and multivariate analysis (Table 4). The only factor associated with reduced wound 
infections on multivariate analysis was pulse irrigation of laparotomy wounds (Odds ratio: $0.3(0.1-0.9) \mathrm{p}=0.031)$. Length of stay of 2 weeks or longer was independently associated with wound infections in this series (Odds ratio: $7.6(2.4-24.9) \mathrm{p}=0.001$ ).

\section{DISCUSSION}

Wound infection rates relate to a variety of factors, some of which are potentially preventable. Infection rates after major upper gastrointestinal surgery range from 10 to $30 \%{ }^{19,20}$ These infections remain a major cause of post-operative morbidity and a focus of surgical improvement strategies. ${ }^{19,21,22}$ A number of randomized trials have identified factors that may lead to reduced infection rates. Some notable findings include antibiotic administration, use of alcohol based chlorhexadine prepping solution, and abdominal wound barriers. ${ }^{6-12}$ Irrigation of wounds following high risk surgery may represent a simple method of reducing laparotomy wound infections, but had not been studied in a randomized fashion until this report.

Given the large number of factors that have been implicated in the development of wound infections, controlling for all variables was difficult and was overcome partly by the sample size and randomization strategy. We adopted universally enforced standard of care measures to reduce wound infections in this study, including routine antibiotic administration and clipping hair immediately before surgery. ${ }^{5,23} \mathrm{We}$ also controlled for distribution of patients with diabetes and maintained tight perioperative glycemic control to minimize its impact on SSI. ${ }^{24}$ Importantly, we also implemented a consistent anesthesia protocol standardizing antiemetic prophylaxis and the intraoperative fractional inspired oxygen concentration, although recent data 
has shown that neither of these variables is associated with an increased risk of SSI. ${ }^{25-}$ ${ }^{28}$ We did note that significantly more patients with drain tubes were assigned to the standard group, but this was not found to be associated with increased risk of infection on multivariate analysis. Similarly differences were noted in the type of incision in each group, which also was not associated with an increase or decrease risk of wound infections.

Wound irrigation is not a universally enforced standard-of-care preventative measure, even though studies have shown it to remove loosely attached cellular debris and reduce bacterial contamination counts. ${ }^{15,17}$ It is accepted that contamination of wounds by microorganisms, ${ }^{29}$ and the presence of necrotic tissue within the wound can lead bacterial overgrowth. ${ }^{29,30}$ The irrigation of wounds appears to be a simple technique to reduce infection rates and the addition of pressure to the irrigation has an additive effect ${ }^{17,31}$. A standard irrigation of pressure of close to but not exceeding 15 psi was tested, given that pressures beyond 15 psi may produce tissue injury and increase the risk of dissemination of contaminants into surrounding tissues. ${ }^{17}$

In our study, pressurized pulse irrigation of laparotomy wounds was independently associated with reduced SSI. The device is relatively inexpensive, which in our hospital costs less than $\$ 80$ AUS,. The process of wound irrigation using several liters of saline can be accomplished within several minutes. The overall infection rate was however much lower than anticipated. Based on previous studies, we had anticipated an infection rate of $30 \%, 5,18,32$ and subsequently powered the study to identify a $50 \%$ reduction in infection rates. The lower than expected infection rate may relate to the 
use of saline irrigation as a control and overall improved outcomes that are associated with enrollment of patients into a study. In our study design, the control group had 2 liters of normal saline poured into the wounds without agitation prior to skin closure. Surgeons felt that it was not justifiable to avoid irrigation of wounds in the control, despite a lack of convincing evidence of a benefit in prevention of laparotomy wound infections. The saline was simply poured into the wound and was not delivered under any pressured by use of a syringe or other delivery device. Other factors such as diabetes were not associated with increased infection rates in this study and this may relate to the small sample size and our practice of tight peri-operative glycemic control. Other factors reported by others to be associated with wound infections such as obesity ${ }^{33}$ and poor nutrition, using albumin a surrogate marker, ${ }^{34}$ were also not associated with an increase in SSI in this series, which similarly may relate to the small sample size.

Despite significant reductions noted in wound infection rates with the use of pulse irrigation, we can only hypothesize that the mechanism involved is a reduction of bacterial load and debridement of desiccated tissue. ${ }^{29,} 30$ It has been shown previously that necrotic tissue at wound margins impedes wound contraction and provides an environment that facilitates wound infection. ${ }^{35}$ Bacterial cultures were not taken from wounds before after wound irrigation to determine whether pulse irrigation treatment altered overall bacterial count. Bacteria counts could be determined by real-time polymerase chain reaction (qPCR), but was not performed in our study due to cost constraints. Rodeheaver et al. ${ }^{31}$ demonstrated that wound irrigation at a pressure of 15 psi resulted in removal of $84.8 \%$ of wound contaminants, compared with $48.6 \%$ at 
impact pressures of $1 \mathrm{psi}$, which is achieved with simple wound irrigation. It was also a surprise to us that the majority of wound infection, defined according to welldefined criteria, ${ }^{5}$ had mixed skin flora isolated from swabs taken. Staphylococcus aureus was isolated form one case and mixed enteric flora in 3 of 16 cases of SSI. Major SSI that required wound debridement occurred in only 2 of 16 cases, and only one was associated with partial abdominal wall dehiscence.

The use of antibiotics to reduce SSI has been the focus of several studies in the past. ${ }^{6}$, ${ }^{8,9}$ Antibiotics, when given prophylactically, appear to reduce wound infection rates, with most authors suggesting that they be given before surgical incision. ${ }^{36}$ All patients in our series received prophylactic antibiotics on induction of anesthesia. There was however an alarming use of antibiotics beyond 24 hours based on the surgeon's preference. Most reported series do not demonstrate clear benefits of prophylactic antibiotics beyond 24-48 hours. ${ }^{37-40}$ The exact indications for this could not be determined in this study, apart from common finding of early post-operative fever associated with these major abdominal operations. There appeared to be a reluctance to cease antibiotics if patients had a mild post-operative fever. This potentially explains the high rate of negative wound culture rates, since the majority of patients with wound infection were given antibiotics beyond 24 hours postoperatively. Alternatively, low positive bacterial culture rates may be explained by sterile necrosis of desiccated tissues and subsequent associated inflammation producing symptoms and signs of SSI. The majority of wound infections (88\%) occurred in patients administered antibiotics beyond 24 hours. 
Based on this randomized controlled trial, we advocate pressurized pulse irrigation of major laparotomy wounds following prolonged operative procedures ( $>2$ hours). There appears to be no adverse effect with the use of a pulse irrigating device, with the benefit of reduced SSI. This makes it a cost effective infection prevention strategy. 


\section{ACKNOWLEDGEMENT}

We would like to acknowledge Ms Linda Nolasco, Clinical Research Coordinator for her help in the collection of these data, as well as all the surgical interns, registrars and Fellows on the unit. 


\section{DISCLOSURES}

The study was supported by The University of Melbourne, Early Career

Developmental grant, awarded to Dr Mehrdad Nikfarjam. This study was not supported in any manner by Stryker®, and there was no education or research contribution to the department or university. 


\section{LEGENDS}

Figure 1. Flow diagram of the progress through the phases of randomization of patients in this study. Control / Standard group involved 2 litres of saline poured into the subcutaneous tissue without any agitation prior to skin closure. 


\section{REFERENCES}

1. Hollenbeak CS, Murphy DM, Koenig S, et al. The clinical and economic impact of deep chest surgical site infections following coronary artery bypass graft surgery Chest 2000: 118; 397-402

2. Whitehouse JD, Friedman ND, Kirkland KB, et al. The impact of surgical-site infections following orthopedic surgery at a community hospital and a university hospital: adverse quality of life, excess length of stay, and extra cost Infect Control Hosp Epidemiol 2002: 23; 183-189

3. Gaynes RP, Culver DH, Horan TC, et al. Surgical site infection (SSI) rates in the United States, 1992-1998: the National Nosocomial Infections Surveillance System basic SSI risk index Clin Infect Dis 2001: 33 Suppl 2; S69-77

4. Murray BW, Huerta S, Dineen S, et al. Surgical site infection in colorectal surgery: a review of the nonpharmacologic tools of prevention $\mathrm{J}$ Am Coll Surg: $211 ; 812-822$

5. Mangram AJ, Horan TC, Pearson ML, et al. Guideline for prevention of surgical site infection, 1999. Hospital Infection Control Practices Advisory Committee Infect Control Hosp Epidemiol 1999: 20; 250-278; quiz 279-280

6. Fujita S, Saito N, Yamada T, et al. Randomized, multicenter trial of antibiotic prophylaxis in elective colorectal surgery: single dose vs 3 doses of a secondgeneration cephalosporin without metronidazole and oral antibiotics Arch Surg 2007: 142; 657-661

7. Darouiche RO, Wall MJ, Jr., Itani KM, et al. Chlorhexidine-Alcohol versus Povidone-Iodine for Surgical-Site Antisepsis N Engl J Med: 362; 18-26 
8. Itani KM, Wilson SE, Awad SS, et al. Ertapenem versus cefotetan prophylaxis in elective colorectal surgery N Engl J Med 2006: 355; 2640-2651

9. Arnaud JP, Bellissant E, Boissel P, et al. Single-dose amoxycillin-clavulanic acid vs. cefotetan for prophylaxis in elective colorectal surgery: a multicentre, prospective, randomized study. The PRODIGE Group J Hosp Infect 1992: 22 Suppl A; 23-32

10. Fournel I, Tiv M, Soulias M, et al. Meta-analysis of intraoperative povidoneiodine application to prevent surgical-site infection Br J Surg 2010: 97; 16031613

11. Cheng KP, Roslani AC, Sehha N, et al. ALEXIS O-Ring wound retractor vs conventional wound protection for the prevention of surgical site infections in colorectal resections(1) Colorectal Dis 2012: 14; e346-351

12. Reid K, Pockney P, Draganic B, et al. Barrier wound protection decreases surgical site infection in open elective colorectal surgery: a randomized clinical trial Dis Colon Rectum 2010: 53; 1374-1380

13. Hughes MS, Moghadamian ES, Yin LY, et al. Comparison of bulb syringe, pressurized pulsatile, and hydrosurgery debridement methods for removing bacteria from fracture implants Orthopedics: 35; e1046-1050

14. Chikawa T, Sakai T, Bhatia NN, et al. Retrospective study of deep surgical site infections following spinal surgery and the effectiveness of continuous irrigation Br J Neurosurg: 25; 621-624

15. Hargrove R, Ridgeway S, Russell R, et al. Does pulse lavage reduce hip hemiarthroplasty infection rates? J Hosp Infect 2006: 62; 446-449 
16. Watanabe M, Sakai D, Matsuyama D, et al. Risk factors for surgical site infection following spine surgery: efficacy of intraoperative saline irrigation $\mathbf{J}$ Neurosurg Spine 2010: 12; 540-546

17. Luedtke-Hoffmann KA, Schafer DS Pulsed lavage in wound cleansing Phys Ther 2000: 80; 292-300

18. Nikfarjam M, Kimchi ET, Gusani NJ, et al. Reduction of surgical site infections by use of pulsatile lavage irrigation after prolonged intra-abdominal surgical procedures Am J Surg 2009: 198; 381-386

19. Jarvis WR Benchmarking for prevention: the Centers for Disease Control and Prevention's National Nosocomial Infections Surveillance (NNIS) system experience Infection 2003: 31 Suppl 2; 44-48

20. Dominioni L, Imperatori A, Rotolo N, et al. Risk factors for surgical infections Surg Infect (Larchmt) 2006: 7 Suppl 2; S9-12

21. Horan TC, Culver DH, Gaynes RP, et al. Nosocomial infections in surgical patients in the United States, January 1986-June 1992. National Nosocomial Infections Surveillance (NNIS) System Infect Control Hosp Epidemiol 1993: $14 ; 73-80$

22. Bratzler DW The Surgical Infection Prevention and Surgical Care Improvement Projects: promises and pitfalls Am Surg 2006: 72; 1010-1016; discussion 1021-1030, 1133-1048

23. Tanner J, Moncaster K, Woodings D Preoperative hair removal: a systematic review J Perioper Pract 2007: 17; 118-121, 124-132

24. Ata A, Lee J, Bestle SL, et al. Postoperative hyperglycemia and surgical site infection in general surgery patients Arch Surg 2010: 145; 858-864 
25. Meyhoff CS, Wetterslev J, Jorgensen LN, et al. Effect of high perioperative oxygen fraction on surgical site infection and pulmonary complications after abdominal surgery: the PROXI randomized clinical trial JAMA 2009: 302; $1543-1550$

26. Staehr AK, Meyhoff CS, Henneberg SW, et al. Influence of perioperative oxygen fraction on pulmonary function after abdominal surgery: a randomized controlled trial BMC Res Notes 2012: 5; 383

27. Waldron NH, Jones CA, Gan TJ, et al. Impact of perioperative dexamethasone on postoperative analgesia and side-effects: systematic review and metaanalysis Br J Anaesth 2013: 110; 191-200

28. Eberhart LH, Holdorf S, Albert US, et al. Impact of a single perioperative dose of dexamethasone on the incidence of surgical site infections: a casecontrol study J Obstet Gynaecol Res 2011: 37; 1807-1812

29. Daltrey DC, Rhodes B, Chattwood JG Investigation into the microbial flora of healing and non-healing decubitus ulcers J Clin Pathol 1981: 34; 701-705

30. Constantine BE, Bolton LL A wound model for ischemic ulcers in the guinea pig Arch Dermatol Res 1986: 278; 429-431

31. Rodeheaver GT, Pettry D, Thacker JG, et al. Wound cleansing by high pressure irrigation Surg Gynecol Obstet 1975: 141; 357-362

32. Lauwers S, de Smet F Surgical site infections Acta Clin Belg 1998: 53; 303 310

33. Hourigan JS Impact of obesity on surgical site infection in colon and rectal surgery Clin Colon Rectal Surg 2012: 24; 283-290

34. Hennessey DB, Burke JP, Ni-Dhonochu T, et al. Preoperative hypoalbuminemia is an independent risk factor for the development of surgical 
site infection following gastrointestinal surgery: a multi-institutional study Ann Surg 2010: 252; 325-329

35. Elek SD Experimental staphylococcal infections in the skin of man Ann N Y Acad Sci 1956: 65; 85-90

36. Junker T, Mujagic E, Hoffmann H, et al. Prevention and control of surgical site infections: review of the Basel Cohort Study Swiss Med Wkly: 142; w13616

37. Ishibashi $\mathrm{K}$, Kuwabara $\mathrm{K}$, Ishiguro $\mathrm{T}$, et al. Short-term intravenous antimicrobial prophylaxis in combination with preoperative oral antibiotics on surgical site infection and methicillin-resistant Staphylococcus aureus infection in elective colon cancer surgery: results of a prospective randomized trial Surg Today 2009: 39; 1032-1039

38. Mohri Y, Tonouchi H, Kobayashi M, et al. Randomized clinical trial of singleversus multiple-dose antimicrobial prophylaxis in gastric cancer surgery $\mathrm{Br} \mathrm{J}$ Surg 2007: 94; 683-688

39. Togo S, Tanaka K, Matsuo K, et al. Duration of antimicrobial prophylaxis in patients undergoing hepatectomy: a prospective randomized controlled trial using flomoxef J Antimicrob Chemother 2007: 59; 964-970

40. DiPiro JT, Welage LS, Levine BA, et al. Single-dose cefmetazole versus multiple dose cefoxitin for prophylaxis in abdominal surgery $\mathbf{J}$ Antimicrob Chemother 1989: 23 Suppl D; 71-77 


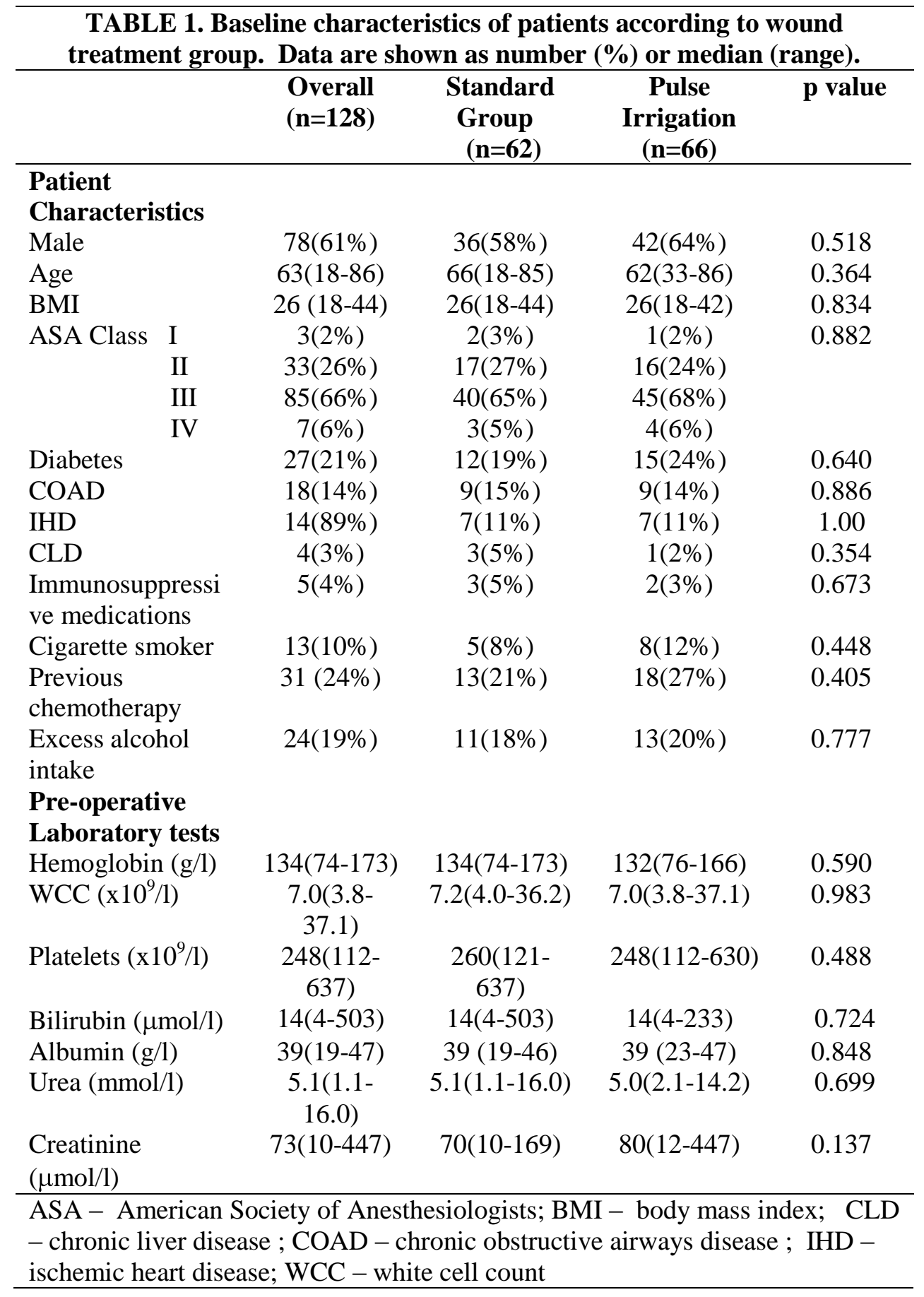

TABLE 2. Operative details and pathology according to wound treatment grouping. Data are presented as number $(\%)$ or median (range).

\begin{tabular}{lcccc}
\hline & $\begin{array}{c}\text { Overall } \\
(\mathbf{n = 1 2 8})\end{array}$ & $\begin{array}{c}\text { Standard } \\
\text { Group } \\
(\mathbf{n = 6 2})\end{array}$ & $\begin{array}{c}\text { Pulse } \\
\text { irrigation } \\
\text { Group } \\
(\mathbf{n = 6 6})\end{array}$ & $\begin{array}{c}\text { Differenc } \\
\text { e } \\
\text { (p value) }\end{array}$ \\
\hline $\begin{array}{l}\text { Malignancy } \\
\begin{array}{l}\text { Surgical indication } \\
\text { Pancreatic }\end{array}\end{array}$ & $99(77 \%)$ & $50(81 \%)$ & $49(74 \%)$ & 0.387 \\
& $54(42 \%)$ & $27(44 \%)$ & $27(41 \%)$ & \\
\hline
\end{tabular}




\begin{tabular}{|c|c|c|c|c|}
\hline Liver/Biliary & $57(45 \%)$ & $30(48 \%)$ & $27(41 \%)$ & 0.232 \\
\hline Other & $17(13 \%)$ & $5(8 \%)$ & $12(18 \%)$ & \\
\hline Drain inserted & $72(57 \%)$ & $41(66 \%)$ & $31(48 \%)$ & $0.045^{*}$ \\
\hline Urinary catheter & $123(96 \%$ & $60(97 \%)$ & $63(96 \%)$ & 1.000 \\
\hline Nasogastric placed & $98(77 \%)$ & $52(84 \%)$ & $46(71 \%)$ & 0.079 \\
\hline Feeding jejunostomy & $5(4 \%)$ & $4(7 \%)$ & $1(2 \%)$ & 0.197 \\
\hline Epidural anesthesia & $44(34 \%)$ & $20(32 \%)$ & $24(36 \%)$ & 0.625 \\
\hline Stapled skin closure & $3(2 \%)$ & $2(3 \%)$ & $1(2 \%)$ & 0.610 \\
\hline $\begin{array}{l}\text { Intraoperative } \\
\text { steroids }\end{array}$ & $13(10 \%)$ & $6(10 \%)$ & $7(11 \%)$ & 0.862 \\
\hline Cases by Surgeon 1 & $60(47 \%)$ & $29(47 \%)$ & $31(47 \%)$ & \\
\hline Cases by Surgeon 2 & $12(9 \%)$ & $6(10 \%)$ & $6(9 \%)$ & \\
\hline Cases by Surgeon 3 & $18(14 \%)$ & $14(23 \%)$ & $4(6 \%)$ & \\
\hline Cases by Surgeon 4 & $16(13 \%)$ & $3(5 \%)$ & $13(20 \%)$ & $0.023 *$ \\
\hline Cases by Surgeon 5 & $11(9 \%)$ & $6(10 \%)$ & $5(8 \%)$ & \\
\hline Cases by Surgeon 6 & $11(9 \%)$ & $4(7 \%)$ & $7(11 \%)$ & \\
\hline Previous laparotomy & $47(37 \%)$ & $24(39 \%)$ & $23(35 \%)$ & 0.651 \\
\hline \multicolumn{5}{|l|}{ Incision type } \\
\hline Midline & $68(53 \%)$ & $28(45 \%)$ & $40(61 \%)$ & \\
\hline Rooftop & $26(20 \%)$ & $11(18 \%)$ & $15(23 \%)$ & $0.033 *$ \\
\hline Reverse L & $34(26 \%)$ & $23(37 \%)$ & $11(17 \%)$ & \\
\hline $\begin{array}{l}\text { Intraoperative } \\
\text { transfusion }\end{array}$ & $16(13 \%)$ & $6(10 \%)$ & $10(15 \%)$ & 0.349 \\
\hline Operative time (min) & $\begin{array}{l}360(120- \\
810)\end{array}$ & $\begin{array}{l}330(150- \\
760)\end{array}$ & $390(120-810)$ & 0.676 \\
\hline \multicolumn{5}{|c|}{${ }^{*} \mathrm{p}<0.05$ Chi-Square/Fisher's exact test } \\
\hline \multicolumn{5}{|c|}{$\begin{array}{l}\text { TABLE 3. Post-operative outcome in patients according to wound } \\
\text { treatment grouping. Data are presented as number }(\%) \text { or median (range). }\end{array}$} \\
\hline & $\begin{array}{l}\text { Overall } \\
(n=128)\end{array}$ & $\begin{array}{c}\text { Standard } \\
\text { Group } \\
(\mathbf{n}=62)\end{array}$ & $\begin{array}{c}\text { Pulse } \\
\text { irrigation } \\
\text { Group } \\
(\mathbf{n}=\mathbf{6 6})\end{array}$ & $\begin{array}{c}\text { Differenc } \\
\mathrm{e} \\
\text { (p value) }\end{array}$ \\
\hline Any complication & $60(47 \%)$ & $26(42 \%)$ & $34(52 \%)$ & 0.278 \\
\hline $\begin{array}{l}\text { Non-wound } \\
\text { related }\end{array}$ & $55(43 \%)$ & $23(37 \%)$ & $32(49 \%)$ & 0.193 \\
\hline Wound infection & $16(13 \%)$ & $12(19 \%)$ & $4(6 \%)$ & $0.032 *$ \\
\hline $\begin{array}{l}\text { Post-operative } \\
\text { transfusion }\end{array}$ & $20(16 \%)$ & $7(11 \%)$ & $13(20 \%)$ & 0.191 \\
\hline $\begin{array}{l}\text { Antibiotics }>24 \\
\text { hours }\end{array}$ & $72(56 \%)$ & $37(60 \%)$ & $35(53 \%)$ & 0.449 \\
\hline Re-laparotomy & $6(5 \%)$ & $3(5 \%)$ & $3(5 \%)$ & 1.0 \\
\hline Readmission & $15(12 \%)$ & $6(10 \%)$ & $9(14 \%)$ & 0.486 \\
\hline $\begin{array}{l}\text { Length of stay } \\
\text { (days) }\end{array}$ & $9(4-71)$ & $9(5-45)$ & $9(4-71)$ & 0.262 \\
\hline
\end{tabular}




\begin{tabular}{|c|c|c|c|c|c|c|}
\hline \multicolumn{7}{|c|}{$\begin{array}{l}\text { TABLE 4. Factors associated with wound infections following laparotomy. Data are } \\
\text { presented as number }(\%) \text { or median (range). }\end{array}$} \\
\hline & \multirow{2}{*}{$\begin{array}{c}\text { Wound } \\
\text { infectio } \\
n \\
(n=16)\end{array}$} & \multirow{2}{*}{$\begin{array}{c}\text { No } \\
\text { wound } \\
\text { infection } \\
(n=112)\end{array}$} & \multicolumn{2}{|c|}{ Univariate } & \multicolumn{2}{|c|}{ Multivariate } \\
\hline & & & $\begin{array}{c}\text { Odds ratio } \\
\text { (Confidence } \\
\text { interval) }\end{array}$ & $p$ value & $\begin{array}{c}\text { Odds ratio } \\
\text { (Confidence } \\
\text { interval) }\end{array}$ & p value \\
\hline \multicolumn{7}{|l|}{ Demographics } \\
\hline Male gender & $13(81 \%)$ & $65(58 \%)$ & $3.1(0.8-11.6)$ & 0.101 & & \\
\hline $\mathrm{BMI} \geq 30$ & $2(13 \%)$ & $25(22 \%)$ & $0.5(0.1-2.3)$ & 0.520 & & \\
\hline Age $\geq 70$ & $6(38 \%)$ & $37(33 \%)$ & $1.2(0.4-3.6)$ & 0.724 & & \\
\hline $\begin{array}{l}\text { Pre-operative } \\
\text { diabetes }\end{array}$ & $1(6 \%)$ & $26(23 \%)$ & $4.3(1.0-19.3)$ & 0.190 & & \\
\hline ASA III/IV & $12(75 \%)$ & $80(71 \%)$ & $1.2(0.4-4.0)$ & 1.0 & & \\
\hline CLD & $2(13 \%)$ & $2(2 \%)$ & $7.9(1.0-60.3)$ & 0.076 & $5.4(0.5-64.9)$ & 0.182 \\
\hline $\begin{array}{l}\text { Hemoglobin } \leq \\
10 \mathrm{~g} / \mathrm{l}\end{array}$ & $2(13 \%)$ & $8(7) \%$ & $1.9(0.4-9.6)$ & 0.612 & & \\
\hline $\begin{array}{l}\text { Bilirubin } \geq 60 \\
\mu \mathrm{mol} / 1\end{array}$ & $2(19 \%)$ & $17(15 \%)$ & $1.3(0.3-5.0)$ & 0.716 & & \\
\hline Albumin $\leq 30 \mathrm{~g} / \mathrm{l}$ & $5(31 \%)$ & $15(13 \%)$ & $2.9(0.9-9.7)$ & 0.066 & $1.1(0.2-4.9)$ & 0.923 \\
\hline $\begin{array}{l}\text { Epidural } \\
\text { anesthesia }\end{array}$ & $5(31 \%)$ & $39(35 \%)$ & $0.9(0.3-2.6)$ & 0.778 & & \\
\hline \multicolumn{7}{|l|}{ Pathology } \\
\hline Malignancy & $12(75 \%$ & $87(78 \%)$ & $0.9(0.3-2.9)$ & 1.0 & & \\
\hline \multicolumn{7}{|l|}{ Surgical } \\
\hline Indication & $7(44 \%)$ & $47(42 \%)$ & & & & \\
\hline Pancreatic & $9(56 \%)$ & $48(43 \%)$ & $\mathrm{n} / \mathrm{a}$ & 0.230 & & \\
\hline Liver/Biliary & $0(0 \%)$ & $17(15 \%)$ & & & & \\
\hline \multicolumn{7}{|l|}{$\begin{array}{l}\text { Other } \\
\text { Operative } \\
\text { details }\end{array}$} \\
\hline Time $\geq 8$ hours & $7(44 \%)$ & $42(38 \%)$ & $1.3(0.4-3.7)$ & 0.630 & & \\
\hline $\begin{array}{l}\text { Blood } \\
\text { transfusion } \\
\text { intraoperative }\end{array}$ & $4(25 \%)$ & $12(11 \%)$ & $2.8(0.8-10.0)$ & 0.218 & & \\
\hline Drain inserted & $11(69 \%)$ & $61(56 \%)$ & $1.8(0.6-5.4)$ & 0.315 & & \\
\hline $\begin{array}{l}\text { Intraoperative } \\
\text { steroids }\end{array}$ & $5(31 \%)$ & $27(24 \%)$ & $1.4(0.5-4.5)$ & 0.537 & & \\
\hline $\begin{array}{l}\text { Previous } \\
\text { laparotomy }\end{array}$ & $8(50 \%)$ & $39(35 \%)$ & $1.9(0.7-5.4)$ & 0.239 & & \\
\hline \multicolumn{7}{|l|}{ Incision type } \\
\hline Midline & $9(56 \%)$ & $59(53 \%)$ & & & & \\
\hline Rooftop & $3(19 \%)$ & $23(21 \%)$ & $\mathrm{n} / \mathrm{a}$ & 1.0 & & \\
\hline Reverse L & $4(25 \%)$ & $30(27 \%)$ & & & & \\
\hline Pulse irrigation & $4(25 \%)$ & $62(55 \%)$ & $0.3(0.08-0.9)$ & $0.032 *$ & $0.3(0.1-0.9)$ & $0.031 \#$ \\
\hline \multicolumn{7}{|l|}{$\begin{array}{l}\text { Post-operative } \\
\text { details }\end{array}$} \\
\hline Re-laparotomy & $2(13 \%)$ & $4(4 \%)$ & $3.9(0.6-23.0)$ & 0.163 & & \\
\hline $\begin{array}{l}\text { Non-wound } \\
\text { complications }\end{array}$ & $11(69 \%)$ & $44(39 \%)$ & $3.4(1.1-10.5)$. & $0.032 *$ & $1.7(0.4-7.2)$ & 0.475 \\
\hline $\begin{array}{l}\text { Postoperative } \\
\text { transfusion }\end{array}$ & $3(19 \%)$ & $17(15 \%)$ & $1.3(0.3-5.0)$ & 0.716 & & \\
\hline Readmission & $2(13 \%)$ & $13(12 \%)$ & $1.1(0.2-5.3)$ & 1.0 & & \\
\hline Length of & $11(69 \%)$ & $26(23 \%)$ & $7.3(2.3-22.9)$ & $<0.001 *$ & $7.6(2.4-24.9)$ & $0.001 \#$ \\
\hline
\end{tabular}


hospital stay $\geq$

14 days

N/A - Not applicable; ASA - American society of anesthesiologists; BMI - body mass index;

CLD - chronic liver disease; $\mathrm{n} / \mathrm{a}$ - non applicable; * $\mathrm{p}<0.05$ Fisher's exact test; $\# \mathrm{p}<0.05$

Multivariate logistic regression. 


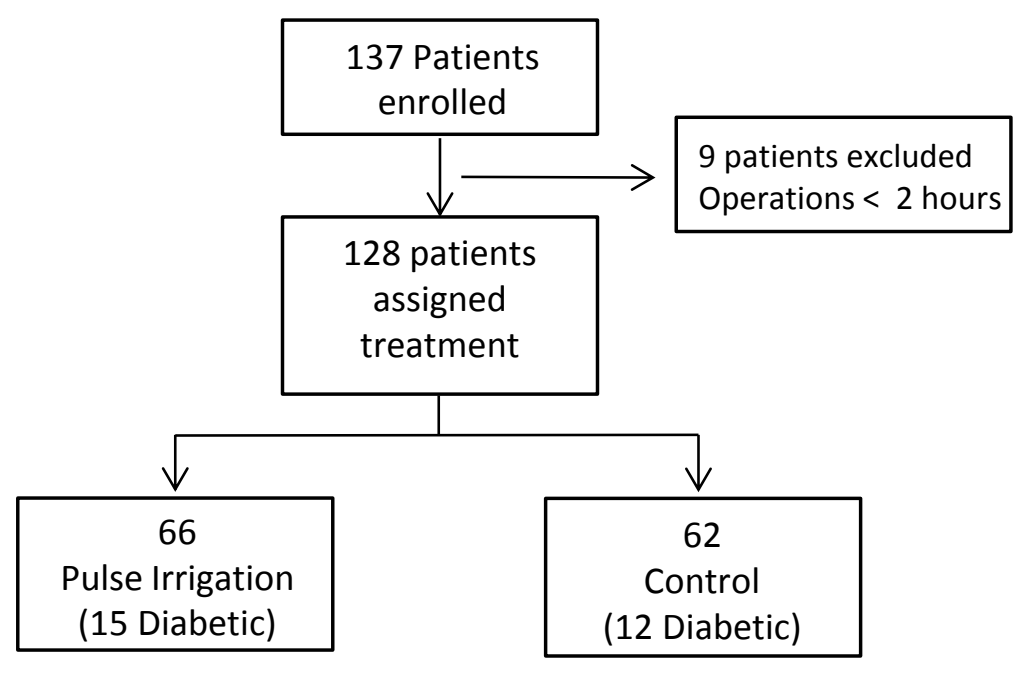

